\title{
To A. L. Shmelkin on the occasion of his 70th birthday
}

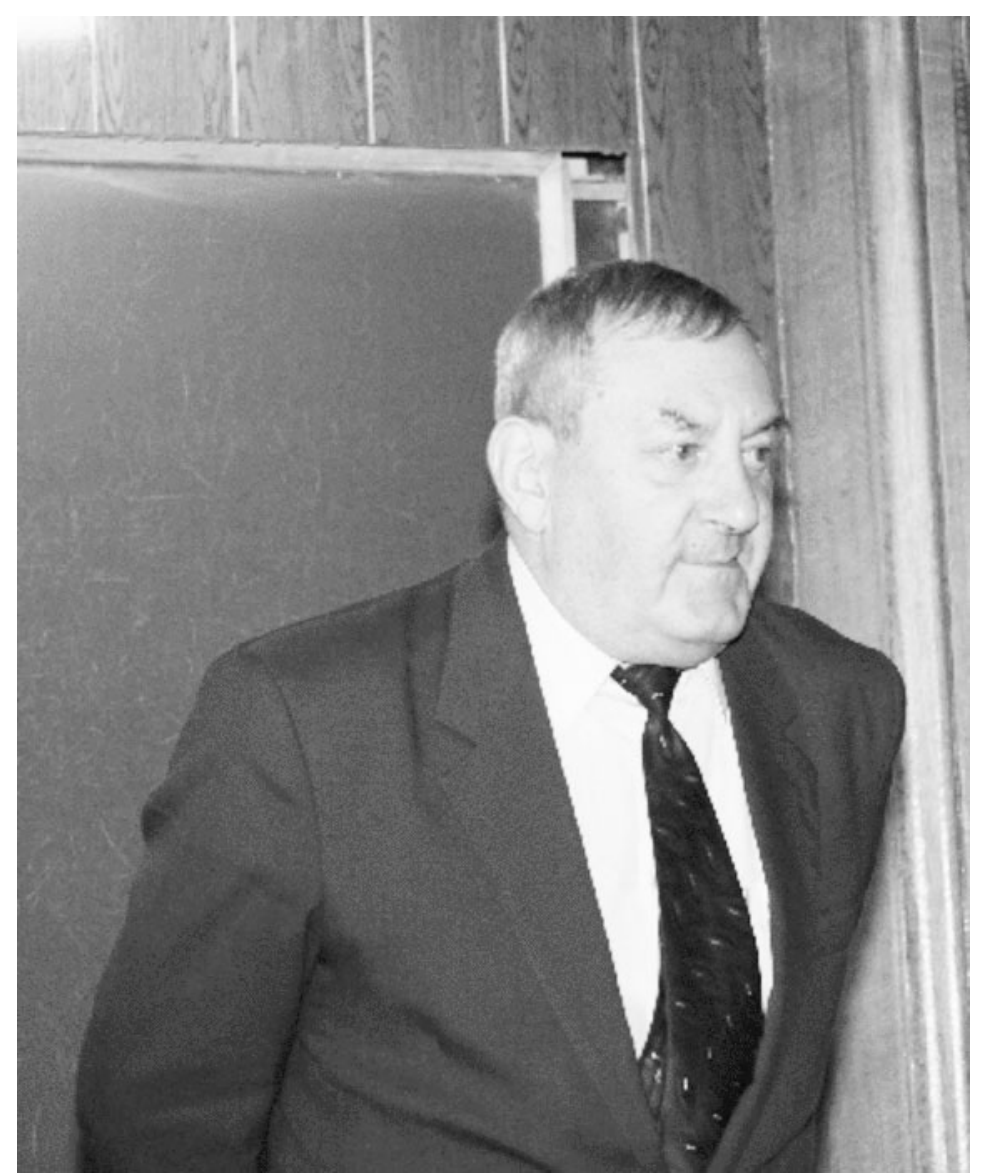

Dear Alfred Lvovich,

In the current issue, the editorial board of the journal is publishing a series of works dedicated to your 70th anniversary. We wish you all the best and every success! 